\title{
Stopping Ultrafiltration Related Arterial Pressure Changes in Hemodialysis Patients
}

\author{
Ahmet Karatas ${ }^{1}$, Emre Erdem $^{2}$ \\ ${ }^{1}$ Department of Nephrology, Ordu University Faculty of Medicine, Ordu, Turkey \\ ${ }^{2}$ Samsun Dialysis Clinic, Samsun, Turkey
}

Received: 02 October 2020, Accepted: 03 December 2020, Published online: 31 December 2020

(C) Ordu University Institute of Health Sciences, Turkey, 2020

\begin{abstract}
Objective: The present study inquired the effects of stopping ultrafiltration on arterial pressure in hemodialysis patients.

Methods: Our study was performed in 92 hemodialysis patients. Ultrafiltration was stopped after the 3rd hour of hemodialysis. Arterial pressure was measured in the supine position at 0,5 , and 10 minutes after ultrafiltration was stopped.

Results: Systolic arterial pressure increased by a mean of $4 \mathrm{~mm} \mathrm{Hg}$ and diastolic arterial pressure increased by a mean of $2 \mathrm{mmHg}$ at 10 minutes after ultrafiltration was stopped. With regard to the difference between mean arterial pressure measured before dialysis and just after stopping ultrafiltration ( 0 . minute), systolic arterial pressure increased by a means of $5 \mathrm{mmHg}$ and diastolic arterial pressure increased by a mean of 2 $\mathrm{mmHg}$ at 10 minutes after ultrafiltration was stopped in the patients with a mean arterial pressure decrease of $\geq 10 \mathrm{mmHg}$. However, stopping ultrafiltration caused no significant changes in the systolic arterial pressure or diastolic arterial pressure of the patients with a mean arterial pressure decrease of $<10 \mathrm{mmHg}$. An important correlation was determined between systolic arterial pressure elevation after stopping ultrafiltration and age, ultrafiltration rate, duration of hemodialysis, gender in the patients with a mean arterial pressure decrease of $\geq 10 \mathrm{mmHg}$. Age and gender were the independent variables, which affected the systolic arterial pressure elevation after stopping ultrafiltration.

Conclusion: In patients with a mean arterial pressure decrease of $\geq 10 \mathrm{mmHg}$, stopping ultrafiltration increases arterial pressure but this is a limited elevation. Stopping ultrafiltration related systolic arterial pressure elevation is more evident in females and in the elderly.
\end{abstract}

Key words: Arterial pressure, hemodialysis, hypotension, ultrafiltration

Suggested Citation: Karatas A, Erdem E. Stopping ultrafiltration related blood pressure changes in hemodialysis patients. Middle Black Sea Journal of Health Science, 2020; 6(3):281-287.

\section{Address for correspondence/reprints:}

Ahmet Karataş

Telephone number: $+90(532) 5790772$

ORCID-ID 0000-0001-9095-6054

E-mail: karatas55@ hotmail.com

DOI: $10.19127 / \mathrm{mbsjohs.804189}$

\section{Introduction}

Hypotension is one of the most common and critical problems in hemodialysis patients (K/DOQI Workgroup, 2005). Hypotension during hemodialysis is strongly associated with ultrafiltration. In hemodialysis, patients, extracellular fluid volume increases owing to weight gain between two dialysis sessions. Too much extracellular fluid is made away with by ultrafiltration during hemodialysis (Kooman et al., 2007). Ultrafiltration rate would be high by virtue of high fluid intake between two dialysis sessions and may cause to be intradialytic hypotension (Saran et al., 2006). Excessive 
ultrafiltration through error evaluation of the patient's dry weight as well may bring about hypotension (Palmer et.al.,2008). The risk of hypotension in the course of hemodialysis is increased in some conditions such as cardiac disorders, diabetes mellitus (DM), agedness, and nitrate usage (K/DOQI Workgroup, 2005; Kooman et al., 2007).

Intradialytic hypotension has been described differently in different studies in the literature. Nonetheless, the European Best Practice Guideline and Kidney Disease Outcomes Quality Initiative (K/DOQI) guidelines have defined intradialytic hypotension as a $\geq 20 \mathrm{mmHg}$ decrease in systolic arterial pressure or a drop off in mean arterial pressure by $10 \mathrm{mmHg}$ and the presence of concomitant symptoms (K/DOQI Workgroup 2005; Kooman et al., 2007). In accordance with European Best Practice Guideline on hemodynamic instability advices, ultrafiltration should be stopped for the treatment of intradialytic hypotension. Stopping ultrafiltration prevents a further fall in blood volume and allow refill of blood volume from the interstitial compartment, by this way hypotension may be improved (Kooman et al., 2007). Although European Best Practice Guideline recommends ultrafiltration should be stopped for hemodialysis hypotension, the effects of stopping ultrafiltration on arterial pressure is indefinite. The present study investigated how arterial pressure was affected by stopping ultrafiltration in hemodialysis patients.

\section{Methods}

\section{Study design and patients}

This present study was confirmed by the Ordu University Clinical Research and Ethics Committee. (Date: 01/11/2018, issue number: 2018/224) Informed consent form was received from the subjects included in the study. All study procedures were performed according to the Declaration of Helsinki. Our study was conducted between April 2019-February 2020.Our study was multicenter. Data collection was done in two places Ordu University Training and Research Hospital hemodialysis center and Samsun D-Med hemodialysis center.

Our study population included 92 hemodialysis patients. Our study was conducted with all patients who agreed to participate in the study in two hemodialysis centers. The patients were above 18 years old and had hemodialysis treatment for at least 3 months. Patients received bicarbonate hemodialysis treatment 3 times a week. The dialysate flow rate was $500 \mathrm{ml} / \mathrm{min}$. The blood flow rate was between 250$400 \mathrm{ml} / \mathrm{min}$. Patients with cardiac dysrhythmia, acute-chronic bleeding, acute infection and hospitalized were not included the study.

Co-morbid conditions of the patients were investigated. The patients were questioned about the presence of hypertension [patients receiving antihypertensive drugs either occasionally or regularly], DM [patients receiving oral antidiabetic and/or insulin] and cardiovascular diseases (CVD) [coronary artery disease, congestive heart failure, cardiac valve replacement, cardiac pacemaker, peripheral vascular disease]. On physical examination, all patients were euvolemic. The dry weight of the patients was recorded, and their systolic arterial pressure and diastolic arterial pressure were measured prior to dialysis in the supine position. Mean arterial pressure was calculated as diastolic arterial pressure plus one-third of (systolic arterial pressure- diastolic arterial pressure) (Abdelfatah et al., 2001). The amount of ultrafiltration was recorded.

Ultrafiltration was stopped at the 3rd hour of hemodialysis and arterial pressure was measured 0,5 and 10 minutes after ultrafiltration was stopped during the patients were in supine position. The difference between mean arterial pressure evaluated at the starting of hemodialysis and mean arterial pressure measured at the 3rd hour of hemodialysis [just after stopping ultrafiltration (0. minute)] was calculated. In hemodialysis patients, blood pressure drops towards the end of hemodialysis due to ultrafiltration. Coll et al. stopped ultrafiltration in their study after the 1st and 3rd hour of hemodialysis and found a blood volume increase of $2 \%$ and $2.3 \%$ respectively (Coll E at al.,2004). In our study, we stopped ultrafiltration at the the 3rd hour of hemodialysis. The patients who were symptomatic due to intradialytic hypotension and patients who were given saline infusion were excluded from the study. We analyzed the patients by dividing them into two groups according to the decline in the mean arterial pressure value (those with a mean arterial pressure decrease of $\geq 10 \mathrm{mmHg}$ and those with a mean arterial pressure decrease of $<10 \mathrm{~mm} \mathrm{Hg}$ ). It was calculated how much arterial pressure increased after 5 and 10 minutes after ultrafiltration was stopped. All arterial pressure measurements were applied using the same automated arterial pressure apparatus (Omron M3 Intellisense, Omron Healthcare, Kyoto, Japan) (Akpolat T et al.,2012).

\section{Statistical analysis}

The SPSS 16 statistics software was used to evaluate the data in our study. The KolmogorovSmirnov test is used to determine whether continuous variables were normally distributed, while descriptive 
analyses were presented as averages and standard deviations for variables with normal distribution. Median and interquartile range (25\%-75\%) were used for variables not distributed normally. The difference between the 0,5 and 10-minute measurements was evaluated by repeated measures ANOVA. In cases in which was a significant difference between the groups was found, pairwise comparisons were made and evaluated using the Bonferroni correction. Normally distributed variables were compared using the paired Student's t test. For correlation analysis, Pearson test was used for variables with normal distribution, Spearman test for variables with at least one non-normal distribution, or sequential variables. Multivariate analysis was carried out using the significant factors identified in univariate analysis. Multiple linear regression analysis was carried out detect the independent predictors that affected the systolic arterial pressure elevation as a result of stopping ultrafiltration. Logarithmic conversion was carried out for the variables that did not show a normal distribution for the multiple linear regression analysis. A $p$ value of $<0.05$ was considered statistically significant.

\section{Results}

Baseline characteristics of the patients are shown in Table 1. Systolic arterial pressure was increased by a mean of $4 \mathrm{~mm} \mathrm{Hg}(\mathrm{p}<0.001)$ and diastolic arterial pressure increased by a mean of $2 \mathrm{mmHg}(\mathrm{p}<0.001)$ at 10 minutes after stopping ultrafiltration. Mean arterial pressure rised by a mean of $2 \mathrm{mmHg}$ $(p<0.001)$ at 10 minutes after stopping ultrafiltration (Table 2).

The patients were dichotomized in regard to the difference between the mean arterial pressure values measured before dialysis and just after stopping ultrafiltration (0th minute) (those with a mean arterial pressure reduce of $\geq 10 \mathrm{mmHg}$ and those with a mean arterial pressure decrease of $<10 \mathrm{mmHg}$ ). Systolic arterial pressure increased by a mean of $5 \mathrm{mmHg}$ $(\mathrm{p}<0.001)$ and diastolic arterial pressure raised by a mean of $2 \mathrm{mmHg}(\mathrm{p}=0.001)$ at 10 minutes after stopping ultrafiltration in the patients with a mean arterial pressure decrease of $\geq 10 \mathrm{mmHg}$. Stopping ultrafiltration caused no prominent changes in the systolic arterial pressure or diastolic arterial pressure of the patients with a mean arterial pressure decrease of $<10 \mathrm{mmHg}$ ( $\mathrm{p}=0.919$ for systolic arterial pressure; $\mathrm{p}=0.297$ for diastolic arterial pressure) (Table 3).
Table 1. Baseline characteristics of the patients

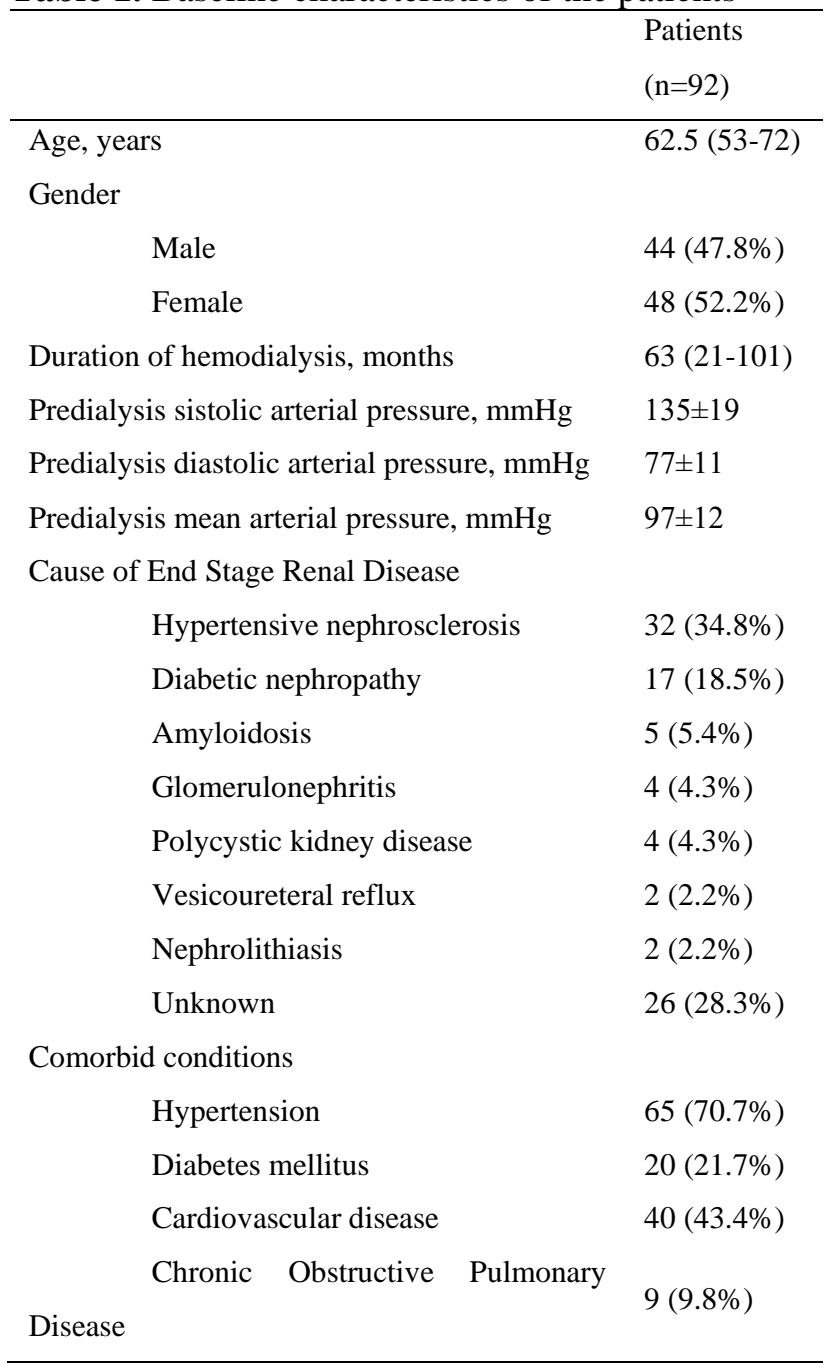

Correlation analysis was fulfilled to inquire the factors associated with arterial pressure elevation as a result of stopping ultrafiltration in the patients with a mean arterial pressure decrease of $\geq 10 \mathrm{mmHg}$. An important correlation was determined between systolic arterial pressure elevation 10 minutes after stopping ultrafiltration and age $(\mathrm{r}=0.3 ; \mathrm{p}=0.012)$, ultrafiltration rate $(\mathrm{r}=-0.302 ; \mathrm{p}=0.012)$, duration of hemodialysis $(\mathrm{r}=-0.270 ; \mathrm{p}=0.025)$, gender $(\mathrm{r}=$ $0.426 ; \mathrm{p}<0.0001)$. There was no significant correlation between stopping ultrafiltration related systolic arterial pressure elevation and the level of predialysis systolic arterial pressure reduction during hemodialysis $(\mathrm{r}=0.49 ; \mathrm{p}=0.692), \mathrm{DM}(\mathrm{r}=0.120 ; \mathrm{p}=$ $0.328)$, HT ( $r=0.29 ; \mathrm{p}=0.813)$, cardiovascular disease $(\mathrm{r}=0.139 ; \mathrm{p}=0.255)$. In the same patient group, there was no significant correlation between the elevation in diastolic arterial pressure 10 minutes after stopping ultrafiltration and age $(\mathrm{r}=0.047$; $\mathrm{p}=0.701)$, ultrafiltration rate $(\mathrm{r}=-0.237 ; \mathrm{p}=0.05)$, duration of hemodialysis $(\mathrm{r}=-0.145 ; \mathrm{p}=0.236)$, 
gender $(r=-0.126 ; p=0.301)$, level of predialysis diastolic arterial pressure reduction during hemodialysis ( $\mathrm{r}=-0.121 ; \mathrm{p}=0.323), \mathrm{DM}(\mathrm{l}=0.42$; $\mathrm{p}=0.729)$, HT $(\mathrm{r}=-0.044 ; \mathrm{p}=0.719)$, cardiovascular disease $(r=-0.006 ; p=0.961)$.

Systolic arterial pressure $(8.55 \pm 7.80$ vs. $1.82 \pm$ $6.78 \mathrm{mmHg} ; \mathrm{p}<0.001)$ elevation 10 minutes after stopping ultrafiltration was more evident in females compared to males in the patients a mean arterial pressure decrease of $\geq 10 \mathrm{mmHg}$. Diastolic arterial pressure $(2.29 \pm 5.12$ vs. $1.54 \pm 4.33 \mathrm{mmHg}$; $\mathrm{p}=$ $0.513)$ increased similarly in both genders.

Multiple linear regression analysis was carried out for determination of the variables that affected the stopping ultrafiltration related arterial pressure elevation. Age and gender were found to be the independent variables that affected the stopping ultrafiltration related systolic arterial pressure elevation (Table 4).

Table 2. The values of arterial pressure at $0^{\text {th }}, 5^{\text {th }}$ and $10^{\text {th }}$ minutes after stopping ultrafiltration $(n=92)$

\begin{tabular}{lccc} 
& $0^{\text {th }}$ minute mean $\pm \mathrm{SD}$ & $5^{\text {th }}$ minute mean $\pm \mathrm{SD}$ & $10^{\text {th }}$ minute mean $\pm \mathrm{SD}$ \\
\hline Sistolic arterial pressure, $\mathrm{mmHg}$ & $105.23 \pm 19.81$ & $107.48 \pm 20.31^{*}$ & $109.07 \pm 19.36^{*}, \uparrow$ \\
Diastolicarterial pressure, $\mathrm{mmHg}$ & $62.33 \pm 10.29$ & $63.12 \pm 10.47$ & $63.58 \pm 10.58^{*}$ \\
Mean arterial pressure, $\mathrm{mmHg}$ & $76.63 \pm 12.31$ & $77.91 \pm 12.41^{*}$ & $78.74 \pm 12.20^{*}, \dagger$ \\
\hline
\end{tabular}

${ }^{*} \mathrm{p}<0.05$ as compared to $0^{\text {th }}$ minute.

$\dagger \mathrm{p}<0.05$ as compared to $5^{\text {th }}$ minute;

Table 3. The values of arterial pressure at $0^{\text {th }}, 5^{\text {th }}$ and $10^{\text {th }}$ minutes after stopping ultrafiltration according to the decrease in mean arterial pressure

\begin{tabular}{|c|c|c|c|c|c|c|}
\hline & \multicolumn{3}{|c|}{$\begin{array}{l}\text { Mean arterial pressure decrease by } \geq 10 \\
\mathrm{mmHg}(\mathrm{n}=69)\end{array}$} & $\begin{array}{l}\text { Mean arterial } \\
\mathrm{mmHg}(\mathrm{n}=23)\end{array}$ & \multicolumn{2}{|c|}{ pressure decrease by $<10$} \\
\hline & $\begin{array}{l}0^{\text {th }} \text { minute } \\
\text { mean } \pm \text { SD }\end{array}$ & $\begin{array}{l}5^{\text {th }} \quad \text { minute } \\
\text { mean } \pm \text { SD }\end{array}$ & $\begin{array}{l}10^{\text {th }} \text { minute } \\
\text { mean } \pm \mathrm{SD}\end{array}$ & $\begin{array}{l}0^{\text {th }} \quad \text { minute } \\
\text { mean } \pm \text { SD }\end{array}$ & $\begin{array}{l}5^{\text {th }} \text { minute } \\
\text { mean } \pm \text { SD }\end{array}$ & $\begin{array}{l}10^{\text {th }} \text { minute } \\
\text { mean } \pm \text { SD }\end{array}$ \\
\hline $\begin{array}{l}\text { Systolic arterial pressure, } \\
\mathrm{mmHg}\end{array}$ & $101.57 \pm 18.27$ & $104.36 \pm 19.48 *$ & $\begin{array}{l}106.71 \pm 18.82 \\
*, \dagger\end{array}$ & $116.22 \pm 20.56$ & $116.83 \pm 20.29$ & $116.13 \pm 19.67$ \\
\hline $\begin{array}{l}\text { Diastolic arterial pressure, } \\
\mathrm{mmHg}\end{array}$ & $59.58 \pm 9.10$ & $60.96 \pm 10.07$ & $61.49 \pm 9.81^{*}$ & $70.60 \pm 9.30$ & $69.60 \pm 8.99$ & $69.82 \pm 10.52$ \\
\hline Mean arterial pressure, $\mathrm{mmHg}$ & $73.57 \pm 10.97$ & $75.42 \pm 11.84 *$ & $76.56 \pm 11.36^{*}$ & $85.81 \pm 11.76$ & $85.34 \pm 11.27$ & $85.26 \pm 12.53$ \\
\hline
\end{tabular}

Table 4. Independent variables affecting the systolic arterial pressure elevation (multiple linear regression analysis)

\begin{tabular}{llllll}
\hline Variables & $\beta$ & Standardized $\beta$ & $95 \%$ CI & \multicolumn{2}{c}{$\mathrm{p}$ value } \\
\cline { 4 - 5 } & & & lower & upper & \\
\hline Age & 25.9 & 0.281 & 5.613 & 46.188 & 0.013 \\
Gender & -5.892 & -0.371 & -9.256 & -2.528 & $<0.001$ \\
Ultrafiltration rate & -0.245 & -0.106 & -0.769 & 0.279 & 0.354 \\
Duration of hemodialysis & -2.073 & -0.137 & -5.246 & 1.099 & 0.196 \\
\hline
\end{tabular}

$\mathrm{CI}=$ Confidence interval

\section{Discussion}

Hypotension is a serious problem in hemodialysis patients. European Best Practice Guideline on hemodynamic instability recommended placing the patient in Trendelenburg position and stopping ultrafiltration for the management of intradialytic hypotension and infusing isotonic saline as long as hypotension is improved with these procedures (Kooman et al., 2007). We have demonstrated that the arterial pressure increased with stopping ultrafiltration in the patients with a mean arterial pressure decrease of $\geq 10 \mathrm{mmHg}$ compared to predialysis values; in addition to, this was a limited elevation. The systolic arterial pressure elevation after stopping ultrafiltration was more evident in females and in the elderly. Presence of DM, HT or cardiovascular disease did not have an effect on systolic arterial pressure elevation. The degree of the decrease in predialysis systolic arterial pressure values during hemodialysis did not affect the stopping ultrafiltration related systolic arterial pressure elevation. No significant changes happen in arterial pressure with stopping ultrafiltration in patients with a mean arterial pressure decrease of $<10 \mathrm{mmHg}$. Excessive fluid gained between two dialysis sessions is removed by ultrafiltration. Blood volume decreases with the removal of excess fluid during ultrafiltration, and this cause a decrease in arterial pressure. Once the blood volume is reduced, the body tries to maintain the arterial pressure within logical limits using 
compensatory mechanisms. When the blood volume decreases, arterial constriction occurs, total peripheral resistance increases, and the arterial pressure increases. Vasoconstriction occurs in large vessels and blood is transferred to the central circulation resulting in cardiac contractility and cardiac output uplift. Moreover, direct autonomic stimulation causes an increase in heart rate and myocardial contraction, and cardiac output is maintained. Hypotension occurs when these recompense mechanisms fail (Kooman et al.,2007; Schneditz et al., 1992; Van der Sande et al.,2000; Thijssen et al., 2013) Compensatory mechanisms for keeping the arterial pressure within exact limits show variation among patients. Hypotension is more widespread in patients over the age of 65 years, patients with low systolic arterial pressure at the beginning of dialysis, diabetic patients, patients with hypoalbuminemia, uremic neuropathy, autonomic dysfunction, cardiovascular problems or severe anemia, and in patients requiring high volume ultrafiltration (K/DOQI Workgroup,2005).

Ultrafiltration is one of the most substantial factors in the development of hypotension in hemodialysis patients. Hypotension rarely occurs in patients that do not undergo ultrafiltration (Barth $\mathrm{C}$ et al.,2003; Thijssen et al., 2013). Ultrafiltration decreases blood volume and inadequate refilling leads to hypovolemia which is suspected to be a major cause for hemodialysis related hypotension (Schneditz et al., 1992; Thijssen et al., 2013). Stopping ultrafiltration increases the plasma volume of the patient, restrains a farther decline in blood volume and may ease refill of blood volume from the interstitial compartment (Kooman et al., 2007). Coll et al. demonstrated that pause of ultrafiltration at the end of the first and third hours of hemodialysis ensure a blood volume increase of $2 \%$ and $2.3 \%$, in order of (Coll E et al., 2004). In the present study, we as well evidenced that arterial pressure increases with stopping ultrafiltration in patients with a mean arterial pressure decrease of $\geq 10 \mathrm{mmHg}$.

Hemodynamic instability European Best Practice Guideline is described as: intradialytic hypotension systolic arterial pressure $\geq 20 \mathrm{mmHg}$ or a $10 \mathrm{mmHg}$ reduction in mean arterial pressure and clinical symptoms that require nursing intervention (Kooman et al.,2007).

When the patients were divided into two groups as regards the decrease in mean arterial pressure, we observed that systolic arterial pressure increased by a mean of $5 \mathrm{mmHg} 10$ minutes after stopping ultrafiltration in the patients with a mean arterial pressure decrease of $\geq 10 \mathrm{mmHg}$; but no significant change was observed in systolic arterial pressure or diastolic arterial pressure in the patients with a mean arterial pressure decrease of $<10 \mathrm{mmHg}$. Normal healthy subjects can tolerate a volume loss up to $20 \%$ without developing hypotension; nevertheless, dialysis patients may improve hypotension even with far less loss in blood volume (Van der Sande et al.,2000; Kooman et al., 2007). The critical blood volume loss at which intradialytic hypotension occurs varies between $2 \%$ and $29 \%$ in hemodialysis patients with a large intra-individual variation. Whilst some hemodialysis patients cannot tolerate small volumes of blood loss, some can tolerate loss up to 29\% (Barth et al., 2003; Kooman et al., 2007). The patients with a mean arterial pressure decrease of $<10 \mathrm{mmHg}$ were able to tolerate blood loss due to ultrafiltration without developing hypotension; therefore, no increase was determined in arterial pressure by stopping ultrafiltration, whereas, as the patients with a mean arterial pressure decrease of $\geq 10 \mathrm{mmHg}$ were less tolerable to fluid removal by ultrafiltration, arterial pressure was decreased by ultrafiltration. Stopping ultrafiltration increased the arterial pressure in such patients as fluid removal was discontinued by cessation of ultrafiltration. Stopping ultrafiltration related arterial pressure elevation has been investigated in other studies. In an earlier study, ultrafiltration was stopped when the patients were in the passive leg raising position (Erdem, 2016). Passive leg lifting was defined as flat passive lifting of the legs above the heart level while the patient was in a supine position (Geerts et al., 2012, Erdem, 2016). In patients with intradialytic hypotension, stopping ultrafiltration at passive leg raising position produced a mean increase of $3 \mathrm{mmHg}$ in systolic arterial pressure and a mean of $1 \mathrm{mmHg}$ increase in diastolic arterial pressure (Erdem, 2016). Different from the above-mentioned study, we stopped ultrafiltration when the patients were in supine position. Passive leg raising as well causes rise in arterial pressure (Erdem, 2016). The reason for a more remarkable increase in arterial pressure with stopping ultrafiltration in the present study is cessation of ultrafiltration in the supine position instead of passive leg raising position. Bradshaw et al. demonstrated a rise in mean arterial pressure by pausing ultrafiltration in the patients with decreased mean arterial pressure during hemodialysis. Ultrafiltration was paused for 10 minutes if the patient's mean arterial pressure was $\leq 70 \mathrm{mmHg}$ or decreased by $\geq 30 \mathrm{mmHg}$ as compared to the values before dialysis. Mean arterial pressure recovered to > $70 \mathrm{mmHg}$ within 10 minutes in $24.6 \%$ cases (Bradshaw et al., 2011). The authors have reported 
that short term interruption of ultrafiltration would lead to vascular refilling and an increase in mean arterial pressure (Bradshaw et al., 2011, Bradshaw et al., 2015).

In our study, the stopping ultrafiltration related systolic arterial pressure elevation was more notable in the elderly and in females. Dialysis-induced hypotension develops when the ultrafiltration related blood volume reduction is greater than the vascular refilling rate. Fluid transmission between interstitial space and vascular space depends on many factors such as capillary hydrostatic pressure, plasma oncotic pressure, capillary permeability, or lymphatic drainage (Thijssen et al., 2013). For this reason, the decrease in blood volume may widely vary among patients even if a similar ultrafiltration rate is applied (Santoro et al.,1998; Thijssen et al., 2013). The vascular space refilling rate may also be highly variable depending on these factors (Sulowicz et al., 2006). More evident arterial pressure improvement with stopping ultrafiltration in the elderly may be related to vascular permeability. Vascular permeability increases in advanced age (Oakley et al., 2014). This may lie behind a more rapid fluid transmission from the interstitial space to the vascular space when the vascular volume decreases and may bring about an elevation in blood pressure. A study investigated the acute influence of drinking water on arterial pressure in healthy participants. Whilst an acute systolic arterial pressure elevation developed in the elderly, systolic arterial pressure elevation did not occur in the young due to drinking water. A more obvious arterial pressure elevation may occur in the elderly with the same amount of fluid (Jordan et al., 2000). Vascular permeability was shown to increase due to estradiol in females (Hox et al., 2015). Hence, stopping ultrafiltration related arterial pressure elevation could have been more evident in females in whom the vascular volume decreased compared to males. There are studies existent indicating that intradialytic hypotension is more frequent in the elderly (K/DOQI Workgroup, 2005; Sands et al., 2014;) and in females (Shoji et al., 2004; Sands et al., 2014). Increased vascular permeability may have a duty in the development of both intradialytic hypotension and stopping ultrafiltration related arterial pressure elevation in females and in the elderly. Further studies are required to inquire this issue.

\section{Conclusion}

In conclusion, no significant change occurs in systolic arterial pressure or diastolic arterial pressure by stopping ultrafiltration in the patients with a mean arterial pressure decrease of $<10 \mathrm{mmHg}$. There is an increase in arterial pressure by stopping ultrafiltration in hemodialysis patients with a mean arterial pressure decrease of $\geq 10 \mathrm{mmHg}$ but this is a limited elevation. Stopping ultrafiltration related systolic arterial pressure elevation is more evident in females and in the elderly. Stopping ultrafiltration may come across the treatment of patients that improve hypotension while hemodialysis.

Ethics Committee Approval: Clinical Studies Ethics Committee of Ordu University, Faculty of Medicine, Decision number: 2018/224 Date: 01.11.2018

Peer-review: Externally peer-reviewed.

Author Contributions: Concept- A.K.; DesignA.K., E.E; Materials- A.K., E.E; Data Collection and Processing- A.K., E.E; Literature Review- A.K., E.E; Writing- A.K., E.E; Critical Review- A.K., E.E.

Conflict of Interest: No conflict of interest was declared by the author.

Financial Disclosure: The author declared that this study hasn't received no financial support.

\section{References}

Abdelfatah AB, Motte G, Ducloux D, Chalopin JM. Determinants of mean arterial pressure and pulse pressure in chronic haemodialysis patients. J Hum Hypertens 2001;15:775-779.

Akpolat T, Erdem E, Aydogdu T. Validation of the Omron M3 Intellisense (HEM-7051-E) upper arm blood pressure monitor, for self-measurement, according to the European Society of Hypertension International Protocol Revision 2010 in a Stage 3-5 chronic kidney disease population. Kidney Blood Press Res 2012;35:8288.

Barth C, Boer W, Garzoni D, Kuenzi T, Ries W, Schaefer R, Schneditz D, Tsobanelis T, van der Sande F, Wojke R, Schilling H, Passlick-Deetjen J. Characteristics of hypotension-prone hemodialysis patients:is there a critical relative blood volüme. Nephrol Dial Transplant 2003; 18:1353-1360.

Bradshaw W, Bennett PN. Asymptomatic Intradialytic Hypotension: The Need for PreEmptive Intervention. Nephrol Nurs J 2015;42:479-485.

Bradshaw W, Ockerby C, Bennett P. Pre-emptively pausing ultrafiltration to minimise dialysis hypotension. Ren Soc Aust J 2011;7:130-134. 
Coll E, Valles M, Torguet P, Bronsoms J, Mate G, Mauri JM. Evaluation of plasma volume variation during different hemodialysis. Nefrologia 2004;24:463-469.

Erdem E. The effects of passive leg raising and ultrafiltration stopping on blood pressure in hemodialysis patients. Int Urol Nephrol 2016;48:877-882.

Geerts BF, van den Bergh L, Stijnen T, Aarts LP, Jansen JR. Comprehensive review: is it better to use the Trendelenburg position or passive leg raising for the initial treatment of hypovolemia? J Clin Anesth 2012;24:668-674.

Hox V, Desai A, Bandara G, Gilfillan AM, Metcalfe DD, Olivera A. Estrogen increases the severity of anaphylaxis in female mice through enhanced endothelial nitric oxide synthase expression and nitric oxide production. J Allergy Clin Immunol 2015;135:729-736.

Jordan J, Shannon JR, Black BK, Ali Y, Farley M, Costa F, Diedrich A, Robertson RM, Biaggioni I, Robertson D. The pressor response to water drinking in humans: a sympathetic reflex? Circulation 2000;101:504-509.

K/DOQI Workgroup: KDOQI clinical practice guidline for cardiovacular disease in dialysis patients. Am J Kidney Dis 2005;45:1-153.

Kooman J, Basci A, Pizzarelli F, Canaud B, Haage P, Fouque D, Konner K, Martin-Malo A, Pedrini L, Tattersall J, Tordoir J, Vennegoor M, Wanner C, ter Wee P, Vanholder R. EBPG guideline on haemodynamic instability. Nephrol Dial Transplant 2007;22:22-44.

Oakley R, Tharakan B. Vascular hyperpermeability and aging. Aging Dis 2014 Apr 1;5(2):114-125.

Palmer BF, Henrich WL. Recent advances in the prevention and management of intradialytic hypotension. J Am Soc Nephrol 2008;19:8-11.

Sands JJ, Usvyat LA, Sullivan T, Segal JH, Zabetakis P, Kotanko P, Maddux FW, Diaz-Buxo JA. Intradialytic hypotension: frequency, sources of variation and correlation with clinical outcome. Hemodial Int 2014;18:415-422.

Santoro A, Mancini E, Zucchelli P. Ultrafiltration behaviour with different dialysis schedules. Nephrol Dial Transplant 1998;13:55-61.

Saran R, Bragg-Gresham JL, Levin NW, Twardowski ZJ, Wizemann V, Saito A, Kimata N, Gillespie BW, Combe C, Bommer J, Akiba T, Mapes DL, Young EW, Port FK. Longer treatment time and slower ultrafiltration in hemodialysis: Associations with reduced mortality in the DOPPS. Kidney Int 2006;69:1222-1228.
Schneditz D, Roob J, Oswald M, Pogglitsch H, Moser $\mathrm{M}$, Kenner T, Binswanger U. Nature and rate of vascular refilling during hemodialysis and ultrafiltration. Kidney Int 1992;42:1425-1433.

Shoji T, Tsubakihara Y, Fujii M, Imai E. Hemodialysis-associated hypotension as an independent risk factor for two-year mortality in hemodialysis patients. Kidney Int 2004;66:12121220.

Sulowicz W, Radziszewki A. Pathogenesis and treatment of dialysis hypotension. Kidney Int 2006;70:36-39.

Thijssen S, Kappel F, Kotanko P. Absolute blood volume in hemodialysis patients: why is it relevant, and how to measure it? Blood Purif 2013;35:63-71.

Van der Sande FM, Kooman JP, Leunissen KM. Intradialytic hypotension-new concepts on an old problem. Nephrol Dial Transplant 2000;15:1746174 